\title{
Visible-Light-Activated Enantioselective Perfluoroalkylation with a Chiral Iridium Photoredox Catalyst
}

\author{
Haohua Huo ${ }^{a}$ \\ Xiaoqiang Huang ${ }^{a}$ \\ Xiaodong Shen ${ }^{a}$ \\ Klaus Harms ${ }^{a}$ \\ Eric Meggers*a,b \\ ${ }^{a}$ Fachbereich Chemie, Philipps-Universität Marburg, \\ Hans-Meerwein-Straße 4, 35043 Marburg, Germany \\ ${ }^{b}$ College of Chemistry and Chemical Engineering, \\ Xiamen University, Xiamen 361005, P. R. of China \\ meggers@chemie.uni-marburg.de
}

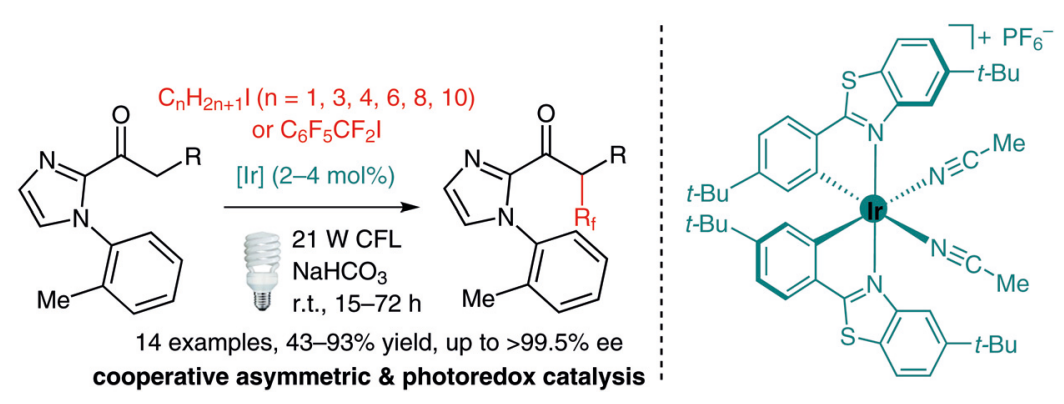

Received: 31.10 .2015

Accepted: 18.11.2015

Published online: 23.12 .2015

DOI: 10.1055/s-0035-1561284; Art ID: st-2015-r0855-c

Abstract A visible-light-activated enantioselective radical perfluoroalkylation of 2-acyl imidazoles with perfluoroalkyl iodides $\left(\mathrm{CF}_{3} \mathrm{I}, \mathrm{C}_{3} \mathrm{~F}_{7} \mathrm{l}\right.$, $\mathrm{C}_{4} \mathrm{~F}_{9} \mathrm{l}, \mathrm{C}_{6} \mathrm{~F}_{13} \mathrm{l}, \mathrm{C}_{8} \mathrm{~F}_{17} \mathrm{l}$ and $\mathrm{C}_{10} \mathrm{~F}_{21} \mathrm{l}$ ) and perfluorobenzyl iodide at the $\alpha$-position of the carbonyl group is reported. Enantioselectivities with up to $>99.5 \%$ ee are achieved. The process uses a dual-function chiral Lewis acid/photoredox catalyst at loadings of $2-4 \mathrm{~mol} \%$ and constitutes a redox-neutral, electron-catalyzed reaction that proceeds via intermediate perfluoroalkyl radicals.

Key words photoredox catalysis, asymmetric catalysis, visible light, perfluoroalkylation, radical reaction, electron catalysis

Visible-light-driven asymmetric catalysis promises to provide an economical and environmentally sustainable strategy for the synthesis of nonracemic chiral molecules. ${ }^{1}$ Photoactivation permits single electron transfer (SET) steps to be induced under very mild reaction conditions, thereby generating intermediate radical ions and radicals with useful reactivities, which expands the mechanistic toolbox for developing novel synthetic transformations. ${ }^{2,3}$ However, the often very high reactivities and concomitant short lifetimes of these odd-electron intermediates comprise a significant challenge for interfacing them with asymmetric catalysis. ${ }^{4}$

Recently, our laboratory reported several examples of cooperative photoredox and asymmetric catalysis using a single chiral iridium ${ }^{5-7}$ or rhodium ${ }^{8}$ complex, which serves both as a photosensitizer to induce and catalyze redox chemistry and, at the same time, as an asymmetric catalyst. We developed a visible-light-activated enantioselective $\alpha$ alkylation of 2-acyl imidazoles with electron-deficient benzyl bromides and phenacyl bromides, ${ }^{5}$ as well as an enantioselective, catalytic trichloromethylation of 2-acyl imidazoles and 2-acylpyridines. ${ }^{7}$ Here, we further advance the dual-function chiral Lewis acid/photoredox catalyst con- cept to develop a photoactivated enantioselective perfluoroalkylation ${ }^{9-11}$ of 2-acyl imidazoles. The photoredox chemistry through intermediate perfluoroalkyl radicals occurs at ambient temperature and requires visible light. High enantioselectivities with up to $>99.5 \%$ ee are observed.

We initiated our study by investigating the enantioselective perfluoroalkylation of 2-acyl imidazoles by using the previously established dual-function chiral Lewis acid/photoredox catalyst $\Lambda$-Ir1 (Table 1$){ }^{5,7}$ When 2-acyl imidazole 1a' reacted with $\mathrm{C}_{4} \mathrm{~F}_{9} \mathrm{I}$ (6 equiv) in the presence of $\mathrm{NaHCO}_{3}$ (1.5 equiv) and $4 \mathrm{~mol} \% \Lambda$-Ir1, the desired $\alpha$-perfluoroalkylation product $\mathbf{2} \mathbf{a}^{\prime}$ was produced in a disappointing yield of $24 \%$ and with unsatisfactory enantioselectivity of $92 \%$ ee (entry 1). Increasing the steric congestion of the 2acyl imidazole by replacing the $N$-Ph substituent $\left(\mathbf{1 a}^{\prime}\right)$ with $N$-(2-MePh) (1a) improved the enantioselectivity but the yield remained low (29\%; entry 2 ).

However, we found that replacing $\Lambda$-Ir1 with the related catalyst $\Lambda$-Ir $\mathbf{2}$ afforded the perfluoroalkylation product $\mathbf{2 b}$ with satisfactory yield (78\%) and excellent enantioselectivity ee (99\%; Table 1 , entry 3 ). The catalyst loading of $\Lambda$-Ir2 could even be reduced to $2 \mathrm{~mol} \%$ without affecting the performance (entry 4). Control experiments conducted either in the absence of the catalyst or in the dark confirmed that this reaction requires the combined presence of the iridium catalyst and light, otherwise no traces of product were observed (entries 5 and 6). Furthermore, the presence of air completely suppresses the perfluoroalkylation (entry 7), thus supporting the conclusion that this process constitutes a photoredox process that proceeds via intermediate perfluoroalkyl radicals.

The structure of catalyst $\Delta$-Ir2 is shown in Figure 1. This compound bears two cyclometalating 2-phenylbenzothiazole ligands in addition to two exchange-labile acetonitrile groups; the chirality originates exclusively from metal centrochirality and thereby creates a $C_{2}$-symmetrical propeller- 
Table 1 Initial Experiments and Optimization of the Visible-Light-Induced Enantioselective Perfluoroalkylation ${ }^{\mathrm{a}}$

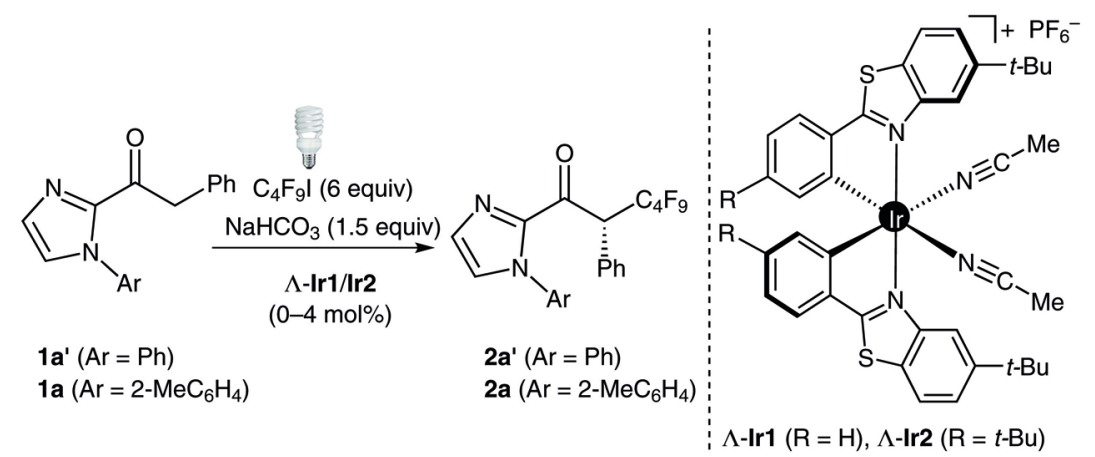

\begin{tabular}{|c|c|c|c|c|c|}
\hline Entry & $\mathrm{Ar}$ & Catalyst (mol\%) & Light $^{\mathrm{c}}$ & Yield (\%) ${ }^{d}$ & ee $(\%)^{\mathrm{e}}$ \\
\hline 1 & $\mathrm{Ph}$ & $\Lambda$-Ir1 (4.0) & yes & 24 & 92 \\
\hline 2 & $2-\mathrm{MeC}_{6} \mathrm{H}_{4}$ & $\Lambda$-Ir1 (4.0) & yes & 29 & 98 \\
\hline 3 & $2-\mathrm{MeC}_{6} \mathrm{H}_{4}$ & $\Lambda-\operatorname{Ir} 2(4.0)$ & yes & 78 & 99 \\
\hline 4 & $2-\mathrm{MeC}_{6} \mathrm{H}_{4}$ & $\Lambda-\operatorname{Ir} 2(2.0)$ & yes & 79 & 99 \\
\hline 5 & $2-\mathrm{MeC}_{6} \mathrm{H}_{4}$ & $\Lambda-\operatorname{Ir} 2(2.0)$ & no & 0 & n.d. \\
\hline 6 & $2-\mathrm{MeC}_{6} \mathrm{H}_{4}$ & none & yes & 0 & n.d. \\
\hline $7^{f}$ & $2-\mathrm{MeC}_{6} \mathrm{H}_{4}$ & $\Lambda-\operatorname{Ir} 2(2.0)$ & yes & 0 & n.d. \\
\hline
\end{tabular}

a Reaction conditions: $1 \mathbf{a}$ or $\mathbf{1 b}$ (1 equiv), $\mathrm{C}_{4} \mathrm{~F}_{9} \mathrm{l}$ (6 equiv), $\mathrm{NaHCO}_{3}$ (1.5 equiv), catalyst ( $0-4$ mol\%), MeOH-THF (4:1), r.t., 34-46 h.

b Catalyst loading (mol\%) in parentheses.

' Light source: $21 \mathrm{~W}$ compact fluorescent lamp (CFL).

d Isolated yield.

e Determined by chiral HPLC analysis; n.d. = not determined.

${ }^{\mathrm{f}}$ Under air atmosphere.

type coordination sphere. ${ }^{12,13}$ Compared with Ir1, Ir2 contains two additional $t$-Bu groups at the phenyl moieties. This modification raises the HOMO and renders Ir2 a better electron donor in both the ground and excited state, ${ }^{14}$ which is apparently beneficial for the perfluoroalkylation reported herein.

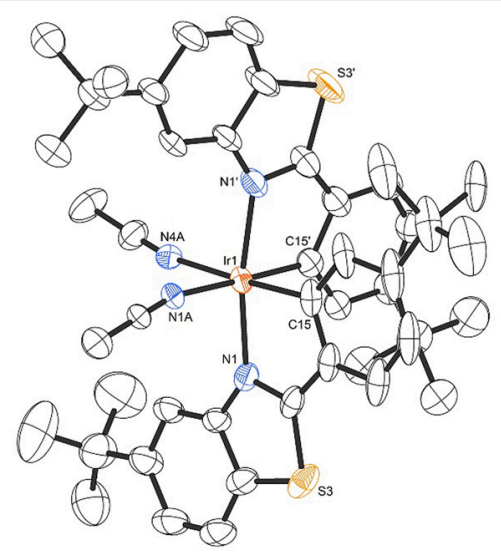

Figure 1 Crystal structure of $\Delta$-Ir2. ORTEP drawing with 30\% probability thermal ellipsoids. The counterion is omitted.
The scope of this reaction with respect to the 2-acyl imidazole substrate is shown in Scheme $1 .{ }^{15}$ Satisfactory yields (59-90\%) and excellent enantioselectivities (96-99\% ee) were achieved for the introduction of a $\mathrm{C}_{6} \mathrm{~F}_{13}$ substituent into the $\alpha$-position of 2-acyl imidazoles, providing the products $\mathbf{3 a}-\mathbf{h}$ bearing aromatic (3a-d) or aliphatic (3e-g) substituents in the $\alpha$-position to the carbonyl group. Even $\mathbf{3 h}$, bearing an aryl ether, was tolerated. We also investigated the scope of the reaction with respect to the perfluoroalkyl groups, synthesizing the perfluoroalkylated products 3i-n. As shown in Scheme 2, $\mathrm{CF}_{3}, \mathrm{C}_{3} \mathrm{~F}_{7}, \mathrm{C}_{4} \mathrm{~F}_{9}, \mathrm{C}_{6} \mathrm{~F}_{13}$, and $\mathrm{C}_{10} \mathrm{~F}_{21}$ substituents can be introduced in a highly enantioselective fashion (3i-m). Furthermore, perfluorobenzylation (3n) was achieved in $93 \%$ yield, providing virtually only a single enantiomer ( $>99.5 \%$ ee), demonstrating the high asymmetric induction that can be achieved in this asymmetric photoredox catalysis.

The proposed mechanism for the perfluoroalkylation involves the intermediate iridium(III) enolate complex that is highlighted in Scheme 3, which is expected to act as the chiral reaction partner for the electron-deficient perfluoroalkyl radicals and, simultaneously, serves as the active photosensitizer $\left(\mathbf{I I}+\mathrm{hv} \rightarrow \mathbf{I I}^{*} \rightarrow \mathbf{I I}^{+}+\mathrm{e}^{-}\right)$. Accordingly, coordina- 


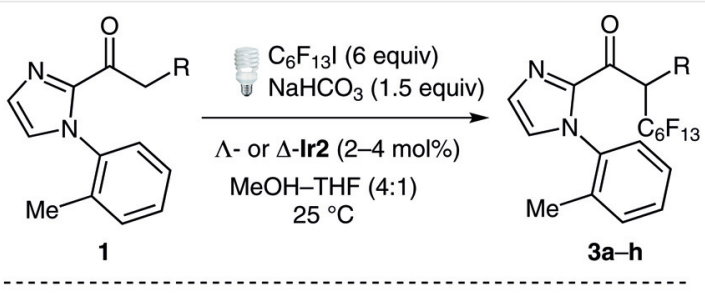<smiles>Cc1ccccc1-n1ccnc1C(=O)[C@H](c1ccccc1)C(F)(F)F</smiles>

3a, 2 mol\% $\Delta-\mathrm{Ir2}, 46 \mathrm{~h}$ $87 \%$ yield, $99 \%$ ee<smiles>Cc1ccccc1-n1ccnc1C(=O)C(CF)c1ccc(Cl)cc1</smiles>

3c, 2 mol\% $\Lambda$-Ir2, 72 h $63 \%$ yield, $96 \%$ ee<smiles>Cc1ccccc1-n1ccnc1C(=O)C(C)C(F)(F)F</smiles>

3e, $4 \mathrm{~mol} \% \Lambda$-Ir2, $24 \mathrm{~h}$ $82 \%$ yield, $97 \%$ ee<smiles>CCCC[C@H](CF)C(=O)c1nccn1-c1c(C)cccc1C(F)(F)F</smiles>

3g, 4 mol\% $\Lambda$-Ir2, 72h $61 \%$ yield, $98 \%$ ee<smiles>COc1ccc(C(C(=O)C(=O)c2nccn2-c2c(C)cccc2C)C(F)(F)F)cc1</smiles>

3b, 2 mol\% $\Lambda$-Ir2, $48 \mathrm{~h}$ $90 \%$ yield, $99 \%$ ee<smiles>Cc1ccccc1-n1ccnc1C(=O)C(CF)c1ccccc1Cl</smiles>

3d, $2 \mathrm{~mol} \% \Lambda$-Ir2, $72 \mathrm{~h}$ $74 \%$ yield, $98 \%$ ee<smiles>CCC(C(=O)c1nccn1-c1ccccc1C)C(F)(F)F</smiles>

3f, $4 \mathrm{~mol} \% \Lambda$-Ir2, $62 \mathrm{~h}$ $59 \%$ yield, $99 \%$ ee<smiles>Cc1ccc(OC(C(=O)c2nccn2-c2ccccc2C)C(F)(F)F)cc1</smiles>

3h, 2 mol\% $\Lambda$-Ir2, 62 h $62 \%$ yield, $98 \%$ ee

Scheme 1 Substrate scope with respect to 2-acyl imidazoles

tion of 2-acyl imidazole substrate $\mathbf{1}$ into $\Lambda$-Ir2 under release of the two acetonitrile ligands generates the substrate-coordinated intermediate I, which, upon deprotonation, subsequently converts into the key intermediate, namely enolate complex II. The electron-rich $\pi$-system of the enolate double bond enables a rapid reaction with the electron-deficient perfluoroalkyl radicals, which themselves are generated by a SET-reduction of the corresponding perfluoroalkyl halides. ${ }^{16}$ The highly stereoselective radical addition generates an intermediate iridium-coordinated ketyl III, which is strongly reducing and converts into iridium-coordinated product IV upon oxidation. Release of the product and coordination to a new substrate then leads to a new catalytic cy-

cle. The electron that is released upon oxidation of the ketyl intermediate (III $\rightarrow \mathbf{I V}+\mathrm{e}^{-}$) either flows into the photoredox cycle by regenerating the oxidized enolate photoredox sensitizer $\left(\mathbf{I I}^{+}+\mathrm{e}^{-} \rightarrow \mathbf{I I}\right)$ or directly reduces a perfluoroalkyl halide substrate and thereby leads to a chain process. This process can be classified as a redox-neutral, electron-transfer-catalyzed (electron-catalyzed) reaction. ${ }^{17,18}$

In summary, we have reported a visible-light-activated, highly enantioselective perfluoroalkylation of 2-acyl imidazoles with perfluoroalkyl iodides and perfluorobenzyl iodide. The process uses a dual-function chiral Lewis acid/photoredox catalyst at loadings of $2-4 \mathrm{~mol} \%$ and constitutes a redox-neutral, electron-catalyzed reaction that proceeds via intermediate perfluoroalkyl radicals. This work demonstrates the generality of the dual-function chiral Lewis acid/photoredox catalyst concept. From the perspective of the catalyst, it is intriguing that the metal center is capable of serving multiple functions at the same time: it constitutes the exclusive center of chirality (only achiral li-

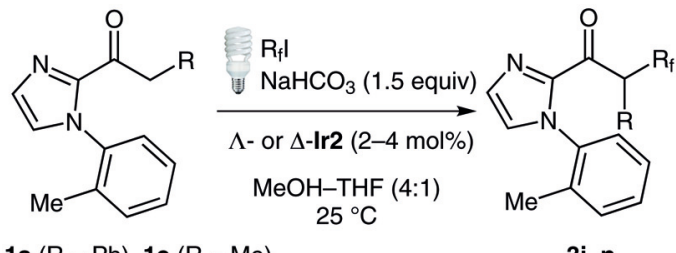

$1 \mathrm{a}(\mathrm{R}=\mathrm{Ph}), 1 \mathrm{e}(\mathrm{R}=\mathrm{Me})$ $3 \mathbf{i}-\mathbf{n}$

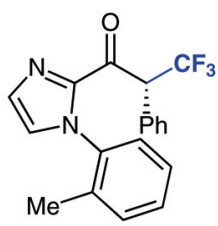

3i, 2 mol\% $\Lambda$-Ir2, $44 \mathrm{~h}$ $43 \%$ yield, $93 \%$ ee<smiles>Cc1cccc(C)c1-n1ccnc1C(=O)C(C(F)(F)F)C(F)(F)C(F)(F)F</smiles>

3k, $2 \mathrm{~mol} \% \Lambda$-Ir2, $24 \mathrm{~h}$ $49 \%$ yield, $95 \%$ ee

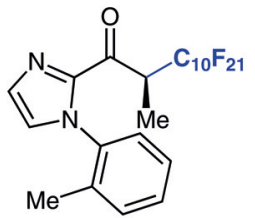

$3 \mathrm{~m}, 4 \mathrm{~mol} \% \Delta-\mathrm{Ir} 2,44 \mathrm{~h}$ $51 \%$ yield, $95 \%$ ee<smiles>Cc1ccccc1-n1ccnc1C(=O)C(C(F)(F)F)C(F)(F)C(F)(F)F</smiles>

3j, 2 mol\% $\Lambda$-Ir2, $45 \mathrm{~h}$ $53 \%$ yield, $95 \%$ ee<smiles>Cc1cccc(C)c1-n1ccnc1C(=O)C(C)C(C(F)F)C(F)F</smiles>
$63 \%$ yield, $95 \%$ ee<smiles>Cc1cccc2c1-n1ccnc1C(=O)C(C(F)(F)c1c(F)c(F)c(F)c(F)c1F)[C@H]2F</smiles>

3n, 2 mol\% $\Lambda$-Ir2, $15 \mathrm{~h}$ $93 \%$ yield, $>99.5 \%$ ee
3I, $2 \mathrm{~mol} \% \Lambda$-Ir2, $24 \mathrm{~h}$

Scheme 2 Substrate scope with respect to perfluoroalkyl iodides and perfluorobenzyl iodide 


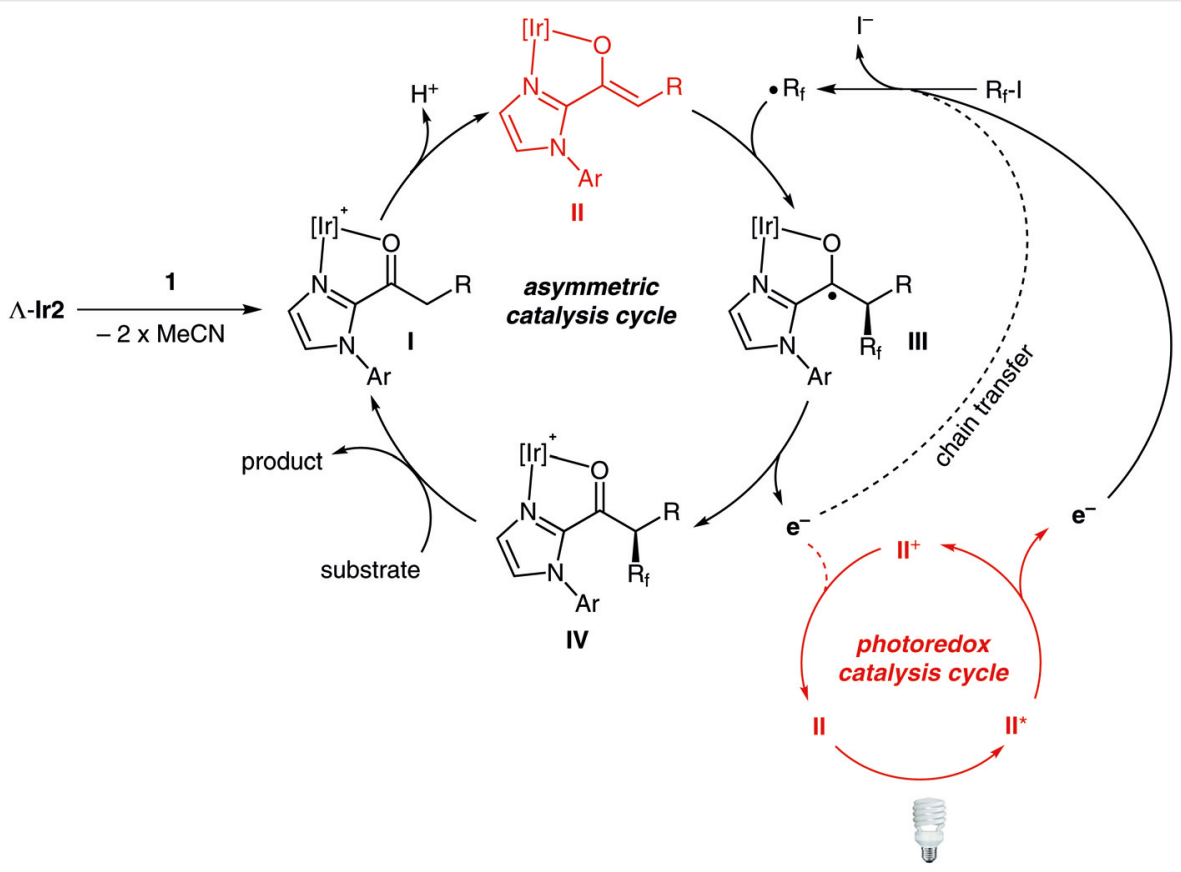

Scheme 3 Plausible mechanism for the photoactivated asymmetric perfluoroalkylation of 2-acyl imidazoles. The proposed mechanism involves the highlighted intermediate iridium(III) enolate complex, which likely serves as the active photosensitizer and the chiral reaction partner for the electrondeficient radicals.

gands), the catalytically active Lewis acid center, and additionally functions as the key component of the photosensitizer that is formed in situ.

\section{Acknowledgment}

H.H. and X.H. contributed equally to this study. This work was supported by the German Research Foundation (ME 1805/11-1) and the Philipps-Universität Marburg. H.H. thanks the China Scholarship Council for a stipend.

\section{Supporting Information}

Supporting information for this article is available online at http://dx.doi.org/10.1055/s-0035-1561284.

\section{References and Notes}

(1) For reviews on asymmetric catalysis through visible-light activation, see: (a) Wang, C.; Lu, Z. Org. Chem. Front. 2015, 2, 179. (b) Meggers, E. Chem. Commun. 2015, 51, 3290. (c) Brimioulle, R.; Lenhart, D.; Maturi, M. M.; Bach, T. Angew. Chem. Int. Ed. 2015, 54, 3872. (d) Peña-López, M.; Rosas-Hernández, A.; Beller, M. Angew. Chem. Int. Ed. 2015, 54, 5006.

(2) For reviews on photoredox catalysis, see: (a) Fagnoni, M.; Dondi, D.; Ravelli, D.; Albini, A. Chem. Rev. 2007, 107, 2725. (b) Zeitler, K. Angew. Chem. Int. Ed. 2009, 48, 9785. (c) Yoon, T. P.; Ischay, M. A.; Du, J. Nat. Chem. 2010, 2, 527. (d) Narayanam, J. M. R.;
Stephenson, C. R. J. Chem. Soc. Rev. 2010, 40, 102. (e) Teplý, F. Collect. Czech. Chem. Commun. 2011, 76, 859. (f) Xuan, J.; Xiao, W.-J. Angew. Chem. Int. Ed. 2012, 51, 6828. (g) Shi, L.; Xia, W. Chem. Soc. Rev. 2012, 41, 7687. (h) Ravelli, D.; Fagnoni, M.; Albini, A. Chem. Soc. Rev. 2012, 42, 97. (i) Reckenthäler, M.; Griesbeck, A. G. Adv. Synth. Catal. 2013, 355, 2727. (j) Prier, C. K.; Rankic, D. A.; MacMillan, D. W. C. Chem. Rev. 2013, 113, 5322. (k) Hari, D. P.; König, B. Angew. Chem. Int. Ed. 2013, 52, 4734. (l) Schultz, D. M.; Yoon, T. P. Science 2014, 343, 1239176.

(3) For reactions involving single-electron transfer, see: Zhang, N.; Samanta, S. R.; Rosen, B. M.; Percec, V. Chem. Rev. 2014, 114, 5848.

(4) For selected examples, see: (a) Nicewicz, D. A.; MacMillan, D. W. C. Science 2008, 322, 77. (b) Nagib, D. A.; Scott, M. E.; MacMillan, D. W. C. J. Am. Chem. Soc. 2009, 131, 10875. (c) Neumann, M.; Füldner, S.; König, B.; Zeitler, K. Angew. Chem. Int. Ed. 2011, 50, 951. (d) DiRocco, D. A.; Rovis, T. J. Am. Chem. Soc. 2012, 134, 8094. (e) Cherevatskaya, M.; Neumann, M.; Füldner, S.; Harlander, C.; Kümmel, S.; Dankesreiter, S.; Pfitzner, A.; Zeitler, K.; König, B. Angew. Chem. Int. Ed. 2012, 51, 4062. (f) Rono, L. J.; Yayla, H. G.; Wang, D. Y.; Armstrong, M. F.; Knowles, R. R. J. Am. Chem. Soc. 2013, 135, 17735. (g) Cecere, G.; König, C. M.; Alleva, J. L.; MacMillan, D. W. C. J. Am. Chem. Soc. 2013, 135, 11521. (h) Bergonzini, G.; Schindler, C. S.; Wallentin, C.-J.; Jacobsen, E. N.; Stephenson, C. R. J. Chem. Sci. 2013, 5, 112. (i) Arceo, E.; Jurberg, I. D.; Álvarez-Fernández, A.; Melchiorre, P. Nat. Chem. 2013, 5, 750. (j) Du, J.; Skubi, K. L.; Schultz, D. M.; Yoon, T. P. Science 2014, 344, 392. (k) Tellis, J. C.; Primer, D. N.; Molander, G. A. Science 2014, 345, 433. (l) Zhu, Y.; Zhang, L.; Luo, S. J. Am. Chem. Soc. 2014, 136, 14642. (m) Gutierrez, O.; Tellis, J. C.; Primer, D. N.; Molander, G. A.; Kozlowski, M. C. J. Am. Chem. Soc. 
2015, 137, 4896. (n) Woźniak, Ł.; Murphy, J. J.; Melchiorre, P. J. Am. Chem. Soc. 2015, 137, 5678. (o) Silvi, M.; Arceo, E.; Jurberg, I. D.; Cassani, C.; Melchiorre, P. J. Am. Chem. Soc. 2015, 137, 6120.

(5) Huo, H.; Shen, X.; Wang, C.; Zhang, L.; Röse, P.; Chen, L.-A.; Harms, K.; Marsch, M.; Hilt, G.; Meggers, E. Nature 2014, 515, 100.

(6) Wang, C.; Zheng, Y.; Huo, H.; Röse, P.; Zhang, L.; Harms, K.; Hilt, G.; Meggers, E. Chem. Eur. J. 2015, 21, 7355.

(7) Huo, H.; Wang, C.; Harms, K.; Meggers, E. J. Am. Chem. Soc. 2015, 137, 9551.

(8) Tan, Y.; Yuan, W.; Gong, L.; Meggers, E. Angew. Chem. Int. Ed. 2015, 54, 13045.

(9) For perfluoroalkylations through photoredox chemistry, see: (a) Nagib, D. A.; Scott, M. E.; MacMillan, D. W. J. Am. Chem. Soc. 2009, 131, 10875. (b) Nagib, D. A.; MacMillan, D. W. C. Nature 2011, 480, 224. (c) Pham, P. V.; Nagib, D. A.; MacMillan, D. W. Angew. Chem. Int. Ed. 2011, 50, 6119. (d) Nappi, M.; Bergonzini, G.; Melchiorre, P. Angew. Chem. Int. Ed. 2014, 53, 4921. (e) Fernández-Alvarez, V. M.; Nappi, M.; Melchiorre, P.; Maseras, F. Org. Lett. 2015, 17, 2676. (f) Sladojevich, F.; McNeill, E.; Börgel, J.; Zheng, S. L.; Ritter, T. Angew. Chem. Int. Ed. 2015, 54, 3712. (g) Filippini, G.; Nappi, M.; Melchiorre, P. Tetrahedron 2015, 71, 4535. (h) Beatty, J. W.; Douglas, J. J.; Cole, K. P.; Stephenson, C. R. J. Nat. Commun. 2015, 6, 7919. (i) Sahoo, B.; Li, J. L.; Glorius, F. Angew. Chem. Int. Ed. 2015, 54, 11577. See also ref. $4 n$.
(10) For a review on metal-mediated radical perfluoroalkylation, see: Barata-Vallejo, S.; Postigo, A. Coord. Chem. Rev. 2013, 257, 3051.

(11) For a recent review on radical trifluoromethylation, see: Studer, A. Angew. Chem. Int. Ed. 2012, 51, 8950.

(12) Shen, X.; Huo, H.; Wang, C.; Zhang, B.; Harms, K.; Meggers, E. Chem. Eur. J. 2015, 21, 9720.

(13) See also: Huo, H.; Fu, C.; Harms, K.; Meggers, E. J. Am. Chem. Soc. 2014, 136, 2990.

(14) Li, J.; Djurovich, P. I.; Alleyne, B. D.; Yousufuddin, M.; Ho, N. N.; Thomas, J. C.; Peters, J. C.; Bau, R.; Thompson, M. E. Inorg. Chem. 2005, 44, 1713.

(15) General photolysis procedure: A dried $10 \mathrm{~mL}$ Schlenk tube was charged with catalyst $\Lambda$-Ir2 or $\Delta$-Ir2 (2 or $4 \mathrm{~mol} \%$ ), $\mathrm{NaHCO}_{3}$ (25.2 $\mathrm{mg}, 0.3 \mathrm{mmol}, 1.1$ equiv), and the corresponding 2 -acyl imidazole $(0.2 \mathrm{mmol}, 1.0$ equiv). The tube was purged with nitrogen and MeOH-THF (4:1, $0.5 \mathrm{~mL})$ was added by using a syringe, followed by the perfluoroalkyl iodide (6-10 equiv). The reaction mixture was degassed in three freeze-pump-thaw cycles, then the vial was sealed and positioned approximately 5 $\mathrm{cm}$ from a $21 \mathrm{~W}$ compact fluorescent lamp (CFL). The reaction was stirred at room temperature for the indicated time (monitored by TLC) under a nitrogen atmosphere.

(16) For a diastereoselective addition of perfluoroalkyl radicals to titanium enolates, see: Herrmann, A. T.; Smith, L. L.; Zakarian, A. J. Am. Chem. Soc. 2012, 134, 6976.

(17) Chanon, M.; Tobe, M. L. Angew. Chem., Int. Ed. Engl. 1982, 21, 1.

(18) Studer, A.; Curran, D. P. Nat. Chem. 2014, 6, 765. 